\title{
PENGUATAN PENDIDIKAN KARAKTER (PPK) BERBASIS BUDAYA ISLAMI SEKOLAH DI MI MUHAMMADIYAH SIDOREJO BANDONGAN
}

\section{STRENGTHENING CHARACTER EDUCATION BASED ON ISLAMIC CULTURE SCHOOL IN MI MUHAMMADIYAH SIDOREJO BANDONGAN}

\author{
${ }^{1}$ Imam Mawardi, ${ }^{2)}$ Norma Dewi Shalikhah, ${ }^{3)}$ Akhmad Baihaqi \\ ${ }^{1)}$ Program Magister Manajemen Pendidikan Islam, ${ }^{2)}$ Program Studi Pendidikan Guru MI, ${ }^{3)}$ Program Studi \\ Pendidikan Agama Islam, Fakultas Agama Islam \\ Universitas Muhammadiyah Magelang \\ Jl. Bambang Soegeng Km.5 Mertoyudan, Magelang \\ Email: mawardirazal@ummgl.ac.id
}

\begin{abstract}
ABSTRAK
Pendidikan karakter tidak bisa dilepaskan dari substansi pendidikan dalam mengatasi berbagai problema anak bangsa. Hal ini sebagaimana dialami juga oleh MIM Sidorejo terdapat beberapa permasalahan yang ditemukan antara lain: (1) Metode pembelajaran guru di kelas dalam mengaitkan substansi materi dengan nilai-nilai pendidikan karakter kurang optimal; (2) Sistem sekolah yang menguatkan nilai pendidikan karakter dalam menumbuhkan dinamika iklim budaya islami sekolah belum terbangun dengan baik. Tujuan dari pengabdian ini adalah meningkatkan kreativitas guru dalam pembelajaran dengan metode dan media pembelajaran yang dapat menginternalisasi nilai-nilai karakter islami, serta dapat mengembangkan budaya sekolah yang islami. Metode yang digunakan Participatory Rural Apraissal (PRA) yang dibagi menjadi tiga tahap yaitu persiapan, pelaksanaan, dan penyusunan laporan. Hasil dari pengabdian ini antara lain 1) menghasilkan teknologi pembelajaran berkarakter islami berupa metode dan media pembelajaran yang didasarkan atas rumusan desain perencanaan program pembelajaran aktif dengan spirit nilai-nilai islami untuk membentuk karakter peserta didik, 2) budaya sekolah islami yaitu melalui penciptaan lingkungan belajar yang kondusif, baik di kelas maupun luar kelas seperti melaksanakan peraturan/tata tertib yang telah ditetapkan bersama antara guru dan tim pengabdian, dan tercipta perilaku positif yang mendukung penguatan literasi dan karakter peserta didik.
\end{abstract}

Kata kunci: model; pendidikan karakter; nilai islami

\begin{abstract}
Character education cannot be separated from the substance of education in overcoming the various problems of the nation's children. This is also experienced by MIM Sidorejo have several problems found include: (1) The method of teacher learning in class in linking the substance of matter with the values of character education is less than optimal; (2) The school system that strengthens the value of character education in fostering the dynamics of the Islamic cultural climate of the school has not been well developed. The purpose of this dedication are to increase teacher creativity in learning with learning methods and media that can internalize the values of Islamic character, and can develop Islamic school culture. The method used by Participatory Rural Apraissal (PRA) is divided into three stages, namely preparation, implementation and preparation of reports. The results of this dedication include 1) producing learning technology with Islamic character in the form of learning methods and media based on the formulation of active learning program planning design with the spirit of Islamic values to shape the character of learners, 2) islamic school culture is through the creation of a conducive learning environment, both in the classroom and outside the classroom such as implementing rules / regulations that have been set jointly between the teacher and the service team, and creating positive behavior that supports the strengthening of literacy and character of students.
\end{abstract}

Keywords: model; character education; Islamic values

Submitted : 9 September 2019 Revision : 5 November 2019 Accepted : 17 Februari 2020 


\section{PENDAHULUAN}

Pendidikan karakter dalam analisis situasi global merupakan kunci dari manifestasi nilai-nilai yang melekat dari keseluruhan proses pendidikan. Oleh karena itu, Kurikulum 2013 sebagai rujukan proses pembelajaran pada satuan pendidikan perlu mengintegrasikan penguatan pendidikan karakter (PPK) di dalamnya. Integrasi tersebut bukan sebagai program tambahan atau sisipan, melainkan sebagai cara mendidik dan belajar bagi seluruh pelaku pendidikan di satuan pendidikan.

Fenomena yang terjadi khususnya di dunia Pendidikan adalah perilaku menyimpang di kalangan pemuda atau pelajar semakin meningkat. Misalnya, pergaulan bebas, narkoba, tawuran dan premanisme. Di samping itu, sejak kebijakan ujian nasional diterapkan sebagai standar kelulusan, perilaku tidak jujur saat ujian telah dilakukan secara berjamaah oleh guru, siswa dan pihak terkait (Kosim, 2011). Kondisi tersebut menunjukkan bahwa pendidikan karakter di sekolah/ madrasah yang selama ini dikembangkan melalui pendidikan agama dan pendidikan kewargaan telah gagal membentuk peserta didik yang berkarakter karena lebih menekankan pada aspek kognitif dan cenderung mengabaikan aspek afektif. Fenomena tersebut mengindikasikan bahwa penguatan pendidikan karakter menjadi mutlak dilakukan agar generasi muda penerus kepemimpinan bangsa bisa diselamatkan dari kerusakan moral.

Peraturan Presiden Nomor 87 tahun 2017 tentang PPK menjadikan pendidikan karakter sebagai platform pendidikan nasional untuk membekali peserta didik sebagai generasi emas tahun 2045 dengan jiwa Pancasila dan karakter yang baik guna menghadapi dinamika perubahan di masa depan (Pasal 2). Perpres ini menjadi landasan awal untuk kembali meletakkan pendidikan karakter sebagai jiwa utama dalam penyelenggaraan pendidikan di Indonesia.

Lembaga pendidikan memegang peran utama untuk menanamkan karakter dan akhlak siswa. Kegiatannya seperti diajarkan tata krama, sopan-santun, kejujuran, rasa tanggung jawab, kerja keras, integritas, disiplin, dan sekaligus solidaritas. Kita berharap sekolah dan madrasah menjadi laboratorium karakter dan akhlak (Dalyono, 2017). PPK merupakan proses pembetukan, trasmisi, transformasi dan pengembangan kemampuan siswa dalam berpikir dan berperilaku sesuai nilai-nilai Pancasila. PPK di madrasah mempunyai fungsi memilah dan memilih budaya Indonesia dan budaya asing yang lebih beradab dan terhormat (Anshori, 2017).

Peran guru, terutama sebagai fasilitator penyelenggaraan PPK, menjadi entry point keberhasilannya, dan sekaligus sebagai wahana pemenuhan kewajiban jam mengajar. Pada dasarnya peran fasilitator guru ini merupakan penjabaran dari kelima unsur besar yang terkandung dalam penyelenggaraan PPK yakni religius, nasionalis, mandiri, gotong royong, dan integritas (Agung, 2017).

PPK pada Satuan Pendidikan Formal dilakukan dengan menggunakan prinsip, yaitu: (a) berorientasi pada berkembangnya potensi peserta didik secara menyeluruh dan terpadu; (b) keteladanan dalam penerapan pendidikan karakter pada masing-masing lingkungan pendidikan; dan (c) berlangsung melalui pembiasaan dan sepanjang waktu dalam kehidupan sehari-hari (Permendikbud, 2018).

Dengan demikian gerakan PPK di lembaga pendidikan dasar Madrasah Ibtidaiyah (MI) berusaha menempatkan nilai karakter sebagai dimensi terdalam pendidikan yang membudayakan dan memberadabkan para pelaku pendidikan. Hal ini sebagai karakterisasi yang dibentuk dari nilai-nilai islami berdasarkan misi pendidikan profetik Rasulullah Muhammad SAW. Misi profetik merupakan sistem yang melekat sebagai spirit sekaligus dasar moral pada keseluruhan pelaksananan proses pendidikan. Dari sinilah budaya islami dikembangkan untuk menciptakan harmoni tata kehidupan di sekolah sebagai peta jalan transformasi pendidikan Islam. Untuk itulah perlunya penguatan pendidikan karakter bagi peserta didik melalui pelatihan dan pendampingan dalam meningkatkan kompetensi mengajar guru, di samping itu juga penciptaan budaya islami sekolah menjadi wahana yang tertib, menggembirakan. Hal inilah yang menjadi harapan ideal dalam membangun kerjasama kemitraan dengan MIM Sidorejo.

MIM Sidorejo dipilih sebagai mitra Program Kemitraan Masyarakat (PKM), dengan alasan karena MIM ini memiliki daya dukung lingkungan yang baik dan kondusif 
untuk pendidikan, serta potensi SDM guru yang bisa dikembangkan dengan baik. Namun beberapa permasalahan yang komplek menjadikan MIM ini sebagai lembaga pendidikan yang tertinggal. Permasalahan yang terdapat di MIM Sidorejo anatara lain: 1) sarana dan prasarana pembelajaran sangat minim, sehingga pembelajaran tidak bisa berjalan secara optimal; 2) kondisi SDM guru dalam katagori rendah dilihat dari kedisiplinan dan pengalaman karena para guru hampir tidak pernah mengikuti pelatihan pengembangan diri melalui penataran dan workshop peningkatan mutu pembelajaran; 3) anggaran untuk pengembangan pendidikan sangat kurang, bahkan unuk menggaji guru yang semuanya swasta sangat minim; 4) sekolah kurang diminati masyarakat, hal ini terindikasi dari jumlah siswa yang minim dari daya tampung yang diharapkan; 5) peserta didik nampak tidak bersemangat dan kurang motivasi dalam menerima pembelajaran dari gurunya, padahal metode yang digunakan sudah bervariasi meskipun masih nampak konvensional dan kaku, hal ini para guru kurang mendapatkan ilmu-ilmu baru dalam pengembangan metode pembelajaran aktif; 6) output peserta didik dalam hal pembentukan karakter keagamaan dan sosial belum menunjukkan sikap yang diharapkan, padahal seharusnya output pendidikan Islam harus lebih baik daripada pendidikan umum.

Oleh karena tujuan dari pengabdian ini adalah meningkatkan kreativitas guru dalam pembelajaran dengan metode dan media pembelajaran yang dapat menginternalisasi nilai-nilai karakter islami, serta dapat mengembangkan budaya sekolah yang islami.

\section{METODE}

Metode pendekatan dalam pengabdian ini adalah metode Participatory Rural Apraissal (PRA). Metode pendekatan PRA dipilih berdasarkan pertimbangan bahwa yang mempunyai atau menghadapi masalah adalah mitra yaitu MI Muhammadiyah Sidorejo Bandongan dengan alasan karena MIM ini memiliki daya dukung lingkungan yang baik dan kondusif untuk pendidikan, serta potensi SDM guru yang bisa dikembangkan dengan baik, namun beberapa permasalahan yang komplek menjadikan MIM ini sebagai lembaga pendidikan yang tertinggal, oleh karena itu keterlibatan mitra dalam penentuan pemecahan masalah dan penyelesaiannya sangat diperlukan. Metode ini bukan sekedar pengkajian, melainkan melibatkan masyarakat sekolah (guru) dalam keseluruhan proses kegiatan sejak mulai mengenal kebutuhan, perencanaan, pelaksanaan, pemantauan sampai mengevaluasi kegiatan.

Dalam hal ini, PRA dalam kegiatan PKM dibagi menjadi tiga tahap yaitu persiapan, pelaksanaan, dan penyusunan laporan. Persiapan terkait dengan identifikasi masalah, penyusunan jadwal kegiatan, dan persiapan piranti keras dan lunak yang dibutuhkan. Pada tahap pelaksanaan berupa sosialisasi, pelatihan/workshop, dan pendampingan. Kegiatan sosialisasi tentang program Penguatan Pendidikan Karakter (PPK) berbasis nilai-nilai islami kegiatan yang dilaksanakan. Kegiatan workshop tentang pengembangan metode dan media pembelajaran berkarakter nilai-nilai islami. Selanjutnya pendampingan manajemen kelas berkarakter islami dan budaya islami sekolah. Tahap terakhir adalah pelaporan.

\section{HASIL DAN PEMBAHASAN}

1. Sosialisasi Program Penguatan Pendidikan Karakter (PPK) Berbasis Nilai-Nilai Islami

Kegiatan sosialisasi ini diikuti oleh seluruh guru MI Muhammadiyah Sidorejo. Sosialisasi progam PPK berbasis nilai-nilai islami ini menjelaskan tentang dasar PPK, tujuan program PPK, nilai-nilai utama PPK, prinsip-prinsip pengembangan PPK, pendekatan PPK, implikasi kebijakan, dan evaluasi tentang relevansi program PPK bagi sekolah dan mengapa kebijakan PPK penting didukung oleh semua pihak.

Kegiatan sosialisasi ini bertujuan agar guru memperoleh pemahaman mengenai pentingnya pendidikan karakter untuk menghadapi tantangan ke depan yang dihadapi peserta didik dalam hal kemajuan ilmu, teknologi, informasi dan komunikasi di abad-21.

Hasil dari kegiatan sosialisasi program PPK berbasis nilai-nilai islami adalah $95 \%$ guru paham program PPK berbasis nilai-nilai islami yang akan diterapkan di MI Muhammadiyah Sidorejo. 
Adapun kegiatan sosialisasi PPK ini ditampilkan pada gambar 1 .

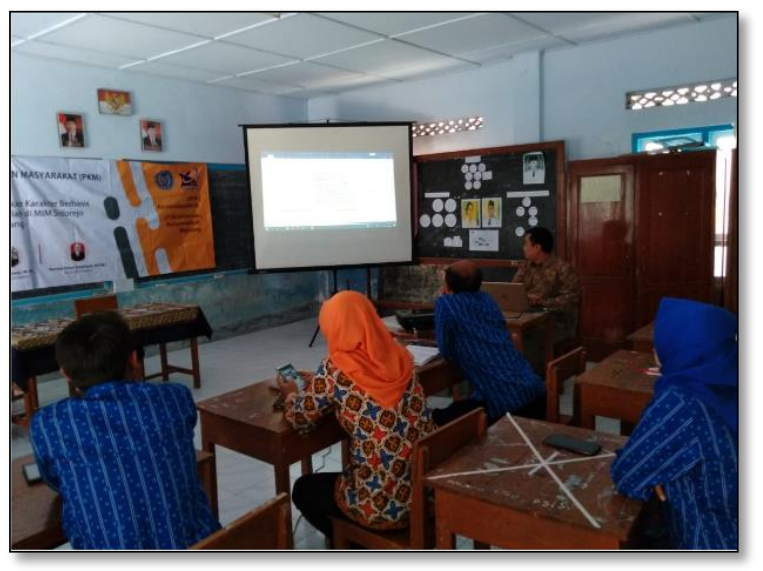

Gambar 1. Sosialisasi PPK Berbasis NilaiNilai Islami

2. Workshop Pengembangan Metode dan Media Pembelajaran Berkarakter Nilai-Nilai Islami

Peserta didik di MI Muhammadiyah Sidorejo nampak tidak bersemangat dan kurang motivasi dalam menerima pembelajaran dari gurunya, padahal metode yang digunakan sudah bervariasi meskipun masih nampak konvensional dan kaku, hal ini dikarenakan para guru kurang mendapatkan ilmu-ilmu baru dalam pengembangan metode pembelajaran aktif dan jarang menggunakan media pembelajaran. Berdasarkan permasalahan tersebut diadakan workshop pengembangan metode dan media pembelajaran berkarakter nilai-nilai islami.

Sessi yang pertama adalah penyampaian materi tentang macam-macam metode pembelajaran dan media pembelajaran. Diawali dengan mengidentifikasi macammacam metode yang sudah sering dilakukan oleh mitra pada waktu kegiatan pembelajaran. Selanjutnya Tim memberikan materi macammacam metode dengan menggunakan pijakan metode pembelajaran Active Learning.

Setelah penjelasan mengenai metode pembelajaran, dilanjutkan penjelasan tentang pembuatan media pembelajaran berbasis IT dengan video scribe dan membuat alat peraga konvensional. Menggunakan teknologi dalam proses pembelajaran mempunyai kelebihan yakni mempermudah dan mempercepat kerja siswa, juga menyenangkan karena siswa berinteraksi dengan gambar, warna-warna, video, suara, dan sesuatu yang instan. Situasi dan kondisi yang menyenangkan ini menjadi faktor penting dan esensial untuk mencapai efektivitas belajar. Di sini teknologi mampu membangkitkan emosi positif dalam proses belajar (Suryadi, 2007).

Kegiatan ini diawali dengan penjelasan tentang pentingnya mengembangkan media pembelajaran atau alat peraga. Mengembangkan media pembelajaran sangat penting dilakukan oleh guru karena pada dasarnya proses pembelajaran merupakan proses komunikasi, dan setiap proses komunikasi membutuhkan media. Tanpa media, proses komunikasi tidak akan terjadi dan proses pembelajaran tidak akan berlangsung secara optimal. Selain membangkitkan motivasi dan pemahaman siswa, melalui media pembelajaran dapat menyajikan karakter nilai-nilai islami melalui tulisan maupun gambar yang menarik.

Setelah penjelasan materi tentang media pembelajaran atau alat peraga, kemudian sessi kedua dilanjutkan praktek pembuatan media pembelajaran dengan memanfaatkan aplikasi video scribe dan membuat alat peraga konvensional. Video scribe adalah software yang dibuat oleh Sparkol Perusahaan di United Kingdom untuk menggunakan animasi papan tulis secara otomatis (Susanti, 2019). Cara membuat media pembelajaran berbasis IT dengan video scribe adalah guru menggunakan laptop kemudian menginstal aplikasi video scribe. Guru mencoba fitur-fitur yang disediakan oleh aplikasi mencoba untuk membuat tulisan menarik, memadukan gambar, desain, memasukkan suara, dan menyisipkan karakter nilai-nilai islami yang ditampilkan di video scribe. Sedangkan cara membuat alat peraga konvensional adalah tim PKM menyiapkan alat dan bahan seperti kertas asturo berwarna, gunting, lem, kain flannel, triplek, dan gergaji. Kemudian guru membuat alat peraga yang sesuai dengan materi pada masingmasing kelas.

Hasil dari wokshop pengembangan metode dan media pembelajaran ini adalah 1) guru memperoleh pemahaman tentang variasi metode pembelajaran dan pengembangan media pembelajaran, 2) guru dapat mempraktekkan metode pembelajaran yang aktif dan kreatif dengan menampilkan media pembelajaran video scribe yang telah dibuat oleh guru, dan 3) dihasilkan media atau alat peraga konvensional yang dibuat oleh guru 
seperti metamorphosis, bagan-bagan bunga, nilai mata uang rupiah, hubungan antar satuan Panjang, jam matematika, dan nama rosul ulul azmi, yang ditampilkan pada gambar 2 dan 3 .

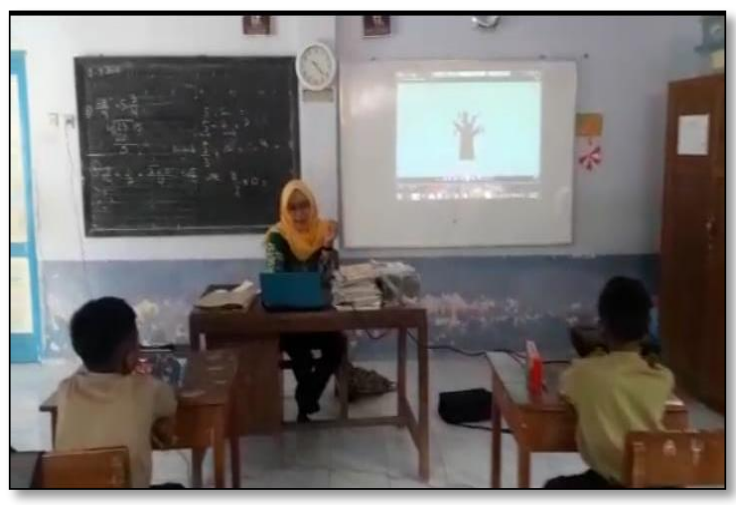

Gambar 2. Praktek Menggunakan Metode Pembelajaran yang Aktif dan Kreatif

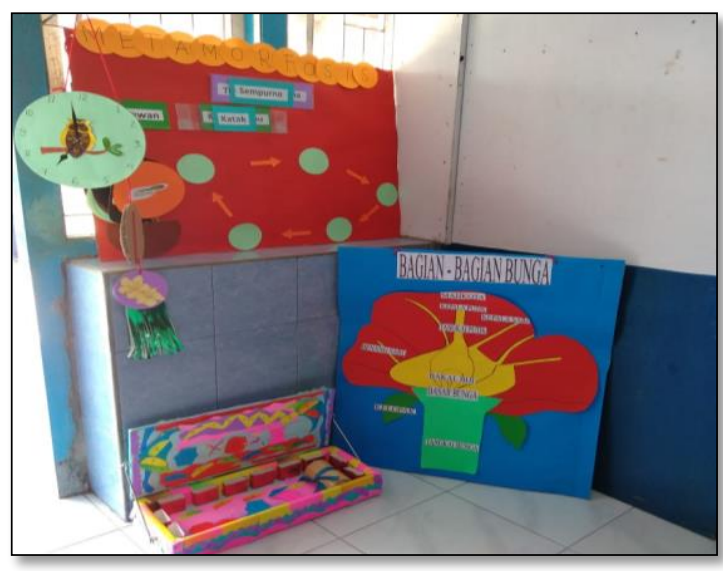

Gambar 3. Media Pembelajaran/Alat Peraga yang Dibuat Guru

3. Pendampingan Manajemen Kelas Berkarakter Islami dan Budaya Islami Sekolah

Salah satu kunci hasil belajar adalah perubahan pemikiran dan perilaku darikebiasaan guru mengajar (pengajaran) ke kebiasaan peserta didik belajar (pembelajaran) di kelas, melalui kemampuan guru dalam manajemen kelas dan mengembangkan metode pembelajaran aktif (Mawardi, 2018). Oleh sebab itu manajemen kelas menjadi tanggung jawab guru bagaimana memoles kelas menjadi kelas yang berkarakter.

Penguatan Pendidikan karakter pada Satuan Pendidikan Formal diselenggarakan dengan mengoptimalkan fungsi kemitraan tripusat pendidikan yang meliputi: keluarga, sekolah dan masyarakat. PPK dilaksanakan dengan pendekatan berbasiskelas, budaya sekolah, dan masyarakat. Kegiatan pendampingan dalam PPK ini adalah manajemen kelas berkarakter islami dan budaya islami sekolah. Kegiatan manajemen kelas yaitu dengan pengelolaan kelas berupa mendesain kelas yang berkarakter dan menerapkan metode pembelajaran yang aktif dan kreatif. Hasil dari pendampingan manajemen kelas adalah tercipta desain kelas berkarakter islami dan guru menggunakan metode pembelajaran yang aktif seperti yang disajikan pada gambar 4.

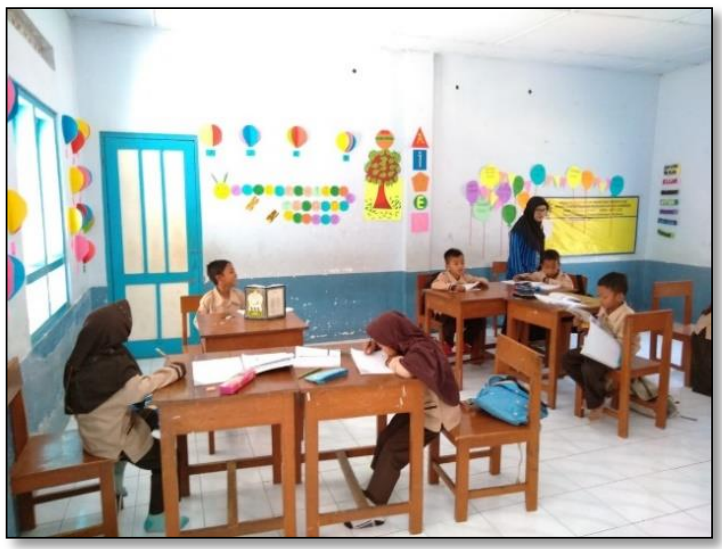

Gambar 4. Kelas Berkarakter Islami

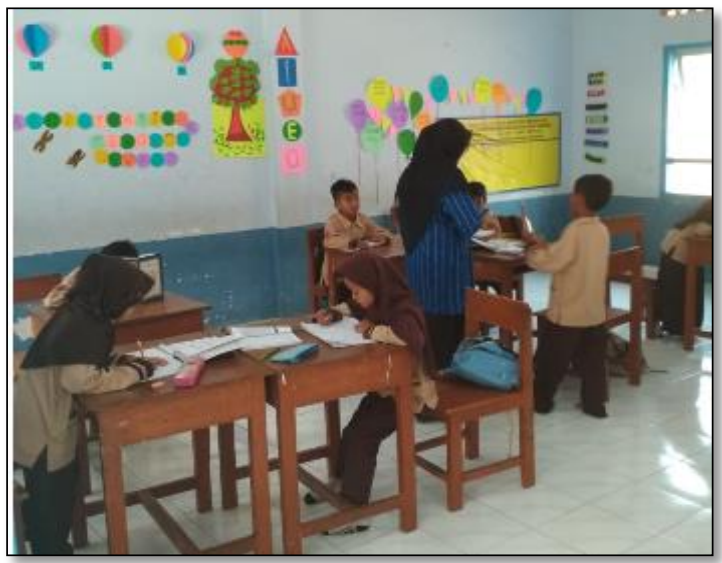

Gambar 5. Metode Pembelajaran Aktif dan Kreatif

Sedangkan pendekatan berbasis budaya sekolah antara lain: menekankan pada pembiasaan nilai-nilai utama dalam keseharian sekolah, memberikan keteladanan antar warga sekolah, melibatkan seluruh pemangku kepentingan pendidikan di sekolah, membangun dan mematuhi norma, peraturan, 
dan tradisi sekolah, mengembangkan keunikan, keunggulan, dan daya saing sekolah sebagai ciri khas sekolah, dan memberi ruang yang luas kepada peserta didik untuk mengembangkan potensi melalui kegiatan literasi. Bagian dari budaya Islami dalam suatu sekolah, diantaranya adalah berpakaian (berbusana) Islami, shalat berjamaah, dzikir secara bersama-sama, Tadarus/membaca Al Qur'an, menebar ukhuwah melalui kebiasaan berkomunikasi secara Islami (senyum, salam, dan sapa), membiasakan Adab yang Baik, melakukan berbagai kegiatan yang dapat mencerminkan suasana keagamaan (Mala, 2015).

Dalam kegiatan pendampingan budaya islami sekolah di MI Muhammadiyah Sidorejo ini yakni dengan melakukan pembiasan karakter islami bagi siswa maupun guru melalui tata tertib berkarakter islami yang telah disusun bersama oleh guru dan tim PKM. Dalam mewujudkan siswa yang berkartakter, selain itu juga didukung dengan jargon-jargon yang dipasang di depan kelas. Hasil dari pembiasaan karakter islami ini adalah 1) siswa sudah tidak sungkan lagi bersalaman dengan masyarakat yang datang ke sekolah, 2) siswa mulai terbiasa membaca do'a masuk masjid masjid, do'a keluar masjid, do'a masuk kamar mandi, dan do'a keluar kamar mandi dengan suara nyaring dihadapan guru, 3) Sholat dhuha menjadi rutin dilaksanakan sebelum pembelajaran dimulai, 4) siswa sudah mulai duduk ketika makan dan minum saat istirahat sekolah, dan 5) budaya literasi mulai dilaksanakan.

\section{SIMPULAN}

Pengabdian dengan menggunakan metode Participatory Rural Apraissal (PRA) ini menghasilkan teknologi pembelajaran berkarakter islami berupa metode dan media pembelajaran yang didasarkan atas rumusan desain perencanaan program pembelajaran aktif dengan spirit nilai-nilai islami untuk membentuk karakter peserta didik, dan budaya sekolah islami yaitu melalui penciptaan lingkungan belajar yang kondusif, baik di kelas maupun luar kelas seperti melaksanakan peraturan/tata tertib yang telah ditetapkan bersama antara guru dan tim pengabdian, dan tercipta perilaku positif yang mendukung penguatan literasi dan karakter peserta didik.

Adapun saran untuk PKM selanjutnya adalah: (1) Guru yang telah mengikuti kegiatan workshop/ pelatihan dan pendampingan ini diharapkan dapat mengimplementasikan metode dan media pembelajaran berkarakter nilai-nilai Islami; serta mampu memanajemen kelas yang berkarakter disesuaikan dengan perkembangan usia peserta didik, dan mampu membudayakan nilai-nilai Islami sebagai budaya sekolah. (2) Diperlukan dukungan dankebijakan nyata dari Universitas Muhammadiyah Magelang dan Majlis Dikdasmen PCM Bandongan untuk menyelenggarakan kegiatan-kegiatan sejenis dalam rangka meningkatkan manajemen sekolah yang bermutu.

\section{UCAPAN TERIMAKASIH}

Tim PKM mengucapkan terimakasih kepada (1) DRPM Kementerian Ristekdikti yang telah memberikan hibah dalam mendukung program PKM 2019 pada peningkatan kualitas pendidikan; (2) Unversitas Muhammadiyah Magelang melalui LP3M atas bimbingan dan berbagai fasilitas yang diberikan dalam mendukung PKM ini; (3) Pimpinan Cabang Muhammadiyah Bandongan Magelang yang telah memberikan izin dalam pelaksanaankegiatan PKM pada lembaga yang dibinanya; (4) Kepala MI Muhammadiyah Sidorejo, dan para guru serta peserta didik yang telah bersedia menjadi mitra dalam program PKM ini. Semoga atas jerih payah dan bantuan menjadi ladang kebaikan dalam meningkatkan mutu pendidikan di Indonesia.

\section{DAFTAR PUSTAKA}

Agung, I. (2017). Peran Fasilitator Guru dalam Penguatan Pendidikan Karakter (PPK). Perspektif Ilmu PEndidikan, 31(2), 106119.

Anshori, I. (2017). Penguatan Pendidikan Karakter di Madrasah. Halaqa: Islamic Education Journal, 1(2), 63-74. https://doi.org/10.21070/halaqa.v1i2.124 3

Dalyono, B. (2017). Implementasi Penguatan Pendidikan Karakter di Sekolah. Bangun Rekaprima, 03(2), 33-42.

Kosim, M. (2011). Urgensi pendidikan 
karakter. Karsa, 9(1).

Mala, A. R. (2015). Membangun budaya islami di sekolah. Irfani, 11(1), 1-13.

Mawardi, I. (2018). Model Pembelajaran Life Skills: Dimensi Penguatan KurikulumPendidikan Agama Islam. Magelang: Unimma Press.

Permendikbud. (2018). Permendikbud Nomor 12 Tahun 2018

Suryadi, A. (2007). Pemanfaatan ICT dalam
Bandongan

Pembelajaran. Jurnal Pendidikan Terbuka Jarak Jauh, 8(1), 83-98.

Susanti, B. (2019). Penggunaan Media Pembelajaran Video Scribe untuk Meningkatkan Minat Belajar Siswa Kelas V Madrasah Ibtidaiyah At-Taqwa Pinang Kota Tangerang Tahun 2018. Naturalistic: Jurnal Kajian Penelitian Pendidikan dan Pembelajaran, 3(2), 387389. 